www.jmscr.igmpublication.org

Index Copernicus Value: 79.54

ISSN (e)-2347-176x ISSN (p) 2455-0450

crossrefDOI: https://dx.doi.org/10.18535/jmscr/v7i2.51

\title{
Correlation between Age of First Child Birth and Axillary Lymph Node Involvement in Carcinoma Breast
}

\author{
Author \\ Dr Rajankumar.T \\ GMC Kozhikode \\ Email: rk2651967@gmail.com, Mobile: 9349940260
}

\begin{abstract}
Background: Carcinoma breast is one of the commonest malignancy in females. Usually it spread to axillary lymph node from there it spread to systemic circulation. in this study we have studied the relation between age at which first child birth and involvement of axillary lymph node

Keywords: carcinoma breast. metastasis. axilla .lymph node.
\end{abstract}

\section{Introduction}

Carcinoma breast is the most common cause of death in middle aged women. The incidence is high in England and Wales. There are so many etiological factors for carcinoma breast including age, genetic, diet, endocrine previous radiation. Breast carcinoma arise from epithelium of the duct system anywhere from nipple end of major duct to the terminal duct unit. The disease may be insitu or invasive type the clinical presentation can be early or late disease the malignancy spread to regional node to the axilla. From there it spread to the systemic circulation and secondary are produced .regional node involvement affect management.

\section{Etiology}

Etiology of Carcinoma breast are obesity, age, gender, family history, nulliparity, menarche, menopause, first child birth number of children. socio economic status, hormonal therapy. Many factors prevent development of malignancy like number of child birth is protective for carcinoma breast and first child birth at the age of 21 is protective than 30 or above. In this study we have tried to study incidence lymph node involvement in relation to the size of the mass

\section{Materials and Methods}

This study is a single center study. We have taken all cases coming in to the outpatient department of govt. medical college Kozhikode. Total number of cases we have taken are 100 . We tried to assess the relation between age at which first child birth and ipsilateral axillary node involvement.

\section{Results}

Table Showing Relation between age of first Child Birth and Axillary Lymph node Involvement 


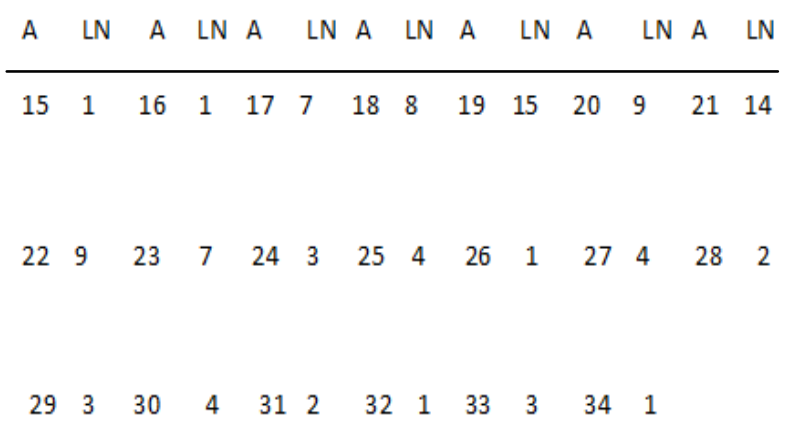

$\mathrm{LN}=$ Number of patients with Axillary lymph node

\section{Discussion}

Axillary node involvement is the most significant prognostic factor in carcinoma breast. We studied 100 patients relation of age of first child birth and axillary lymph node involvement. maximum number of lymph node involved in first child birth is at the age of 19 (15\%).first child birth at the age of $2114 \%$ of patients have axillary lymph node. at 20 it is $9 \% .229 \%$...above the age of 24 lymph node involvement is decreases

\section{Conclusion}

When we correlated the age at which first child birth occurred and involvement of axillary lymph node in carcinoma breast. it is found that carcinoma occuring in a patients with first child birth at young age have high incidence of axillary lymph node involvement

\section{References}

1. Toma S, Bonansi S, puntoni R, Guido $\mathrm{N}$ .Primary tumor, size. Patient age and axillary lymph nodes in breast cancers .Tumori 1986 ;72;259-265

2. Choong PL, deSilva JSC, Dawkins HJS 